\title{
Research on the Interaction of Public Art in Campus Culture
}

\author{
Chao Gao \\ Wuhan University of Science and Technology \\ Wuhan, China
}

\author{
Yan Wang \\ Wuhan University of Science and Technology \\ Wuhan, China
}

\begin{abstract}
The setting of campus public art plays an important role in shaping the humanity and art atmosphere and establishing the acceptance on teacher and student culture and also manifests the special school culture. Because the public art is an emerging artistic concept and we lack the deepen understanding and acknowledgement on it, it will be easy in making it superficial. The design of public art in campus should manifest its "publicity". This article discusses how to manifest the "publicity" of public space art in campus from the perspective of "interaction" so as to ensure the public art to better blend in the school construction and campus culture to create the public space for the interaction between teacher and student on campus.
\end{abstract} body

Keywords-campus culture; public art; interaction; main

\section{INTRODUCTION}

The campus public art mainly refers to the various kinds of art element built in the public space in campus which not only possess strong practicability but also possess certain aesthetic functions and have certain guidance functions on the construction of college culture. Our country is now comprehensively developing the construction of public art in campus.

\section{CAmpus Culture AND CAmpus Public ART}

\section{A. Concept of Campus Culture}

The campus culture is the generic term for material culture, spiritual culture and system culture, etc in campus which is developed by closely interacting with the teaching activities and campus life. The campus culture permeates into every aspect of campus life. Its communication and presentation must be achieved through carriers and special measures. As one of the most important carriers constituting the campus culture system, the public art will be most effective measure. The good education environment has a special education function which can play the imperceptible cultivating function during the quality-oriented education with the objectives of promoting the morality, scientific knowledge, labor skills, physical and mental qualities of students.

\section{B. Concept of Campus Public Art}

The concept of campus public art comes from "public art". On the literal meaning, the word of "public" can be deemed as "popular" and "open". The public art is the artwork or artistic behavior generated in public places and serving the public. The publicity of public art and the campus public places where it is located grant teachers and students the opportunities to get to the art in daily living space. It emphasizes on the conformity of campus environment and human characteristics as well as interaction with main bodies of campus.

\section{Relations between Campus Culture and Campus Public Art}

The core objective for school construction is "culture". When the quality of material civilization has been promoted, the relations between art and life will become closer and closer. The final goal of construction of campus public art is not to become a part of material culture in campus, but to promote the degree of participation of the public and interact with the artworks so as to better meet the spiritual demands of teachers and students.

1) Campus public art demonstrating campus culture: Campus public art is not only the concept of "public space art" but is to put more attention on the regional characteristics, history, development and spiritual culture of schools; it is not just to decorate the campus environment but is more the transmission measure for school culture and the vivid demonstration of school culture. It is manifested in every scene of daily school life of teachers and students and guides them to understand the school culture through the spirit of artistic influence. As the campus public art designs new creative public space and landscape of school, it also introduces new appearance for school culture. The roads in High School Affiliated to Fudan University are decorated with the "clock" with design of matin bell and reading sound as shown in "Fig. 1", with the diameter of about five meters which is fabricated by insetting the colorful marbles. The clock frame is fabricated by two rounds of black marbles. The clock surface is white and the pointer is green pointing to eight points. It is to remind the students that: make your whole day's plans in the morning and that you should have a good start in everyday. There are four stools 
on the circle which can act as the time scale but also can be used by teachers and students for rest.

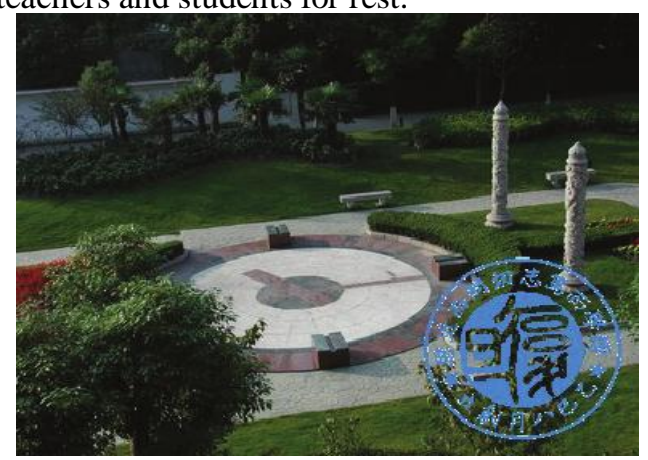

Fig. 1. Picture of pavement of roads in High School Affiliated to Fudan University.

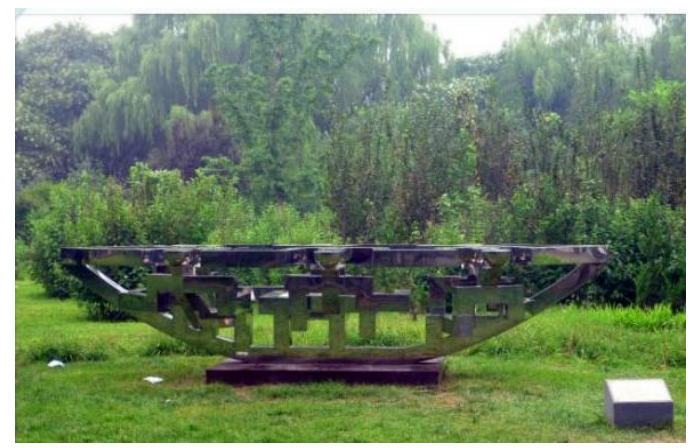

Fig. 2. Sculpture of "Harmoniousness Ark" in campus of Tsinghua University.

2) Campus public art establishing rich expressions of school: The campus public art is the important part in school culture construction and is the most special transmission of school culture. It can enable teachers and students to participate in the construction of school culture to create new school culture transmission and establish the rich expressions of school. There are the public arts mainly reflecting school life such as the sculpture with the theme of "Harmoniousness Ark" in the campus of Tsinghua University as shown in "Fig. 2", which manifests the value orientation of solidarity and making great achievement together through the abstract human mould and complementary Chinese philosophical concepts with binary opposition symbolizing the yin and yang, rigidity and softness as well as heaven and earth, etc which represents the spirits of Chinese nations and the school motto of Tsinghua University.

3) Campus public art representing new orientation of school culture: The campus public art is not just about arts. Besides possessing of artistic values, the publicity is where the values of campus public art lie. The introduction of public art changes the values of students which not only is beyond of symbol characters, provides the education function, but more importantly is the integration of human, public art and environment for establishment of a new kind of culture orientation. The domestic forms of campus public art are relatively singular, comparing with the relatively poor development of contemporary art. However, the criticism and inheritance of traditional art, integration with life and the exploration and breakthrough of new artistic medium of public art are all representing a new kind of artistic form. And the campus artistic forms will certainly be significantly changed and broken through which is the new public artistic concept integrated with public art and the public and will represent the new kind of orientation of school culture.

\section{INTERACTION CHARACTERISTICS OF CAMPUS PUBLIC ART}

The "publicity" of public art is to change the situation of "art of the minority". The interactive practice enables the "publicity" of public art to be realized to the largest extent. Hegel said that, "artists should not completely finish the sculptures first before thinking where to put them, but should come into contact with certain external environment and its space form during design." It can be concluded from above statements that the creation of public space art is not just to place the works in public places but to mutually coordinate, integrate and impact with the public and the public space.

\section{A. Interaction between Public Art and the Public}

The interaction between public art and the public is the important condition to reflect whether the public spatial artworks. In the public art design, the public can also participate in the design and can also play the role of designer. Human is the main body in public space. The public space art manifests the contemporary material and spiritual civilization as well as the interaction experience of "people first" in a manner. The Crown Fountain located in Millennium Park in Chicago as shown in "Fig. 3" consists of two glass brick towers and black granite reflecting pools with computers controlling the fifteen-meter screen which displays the smiles of one thousand different people in turns.

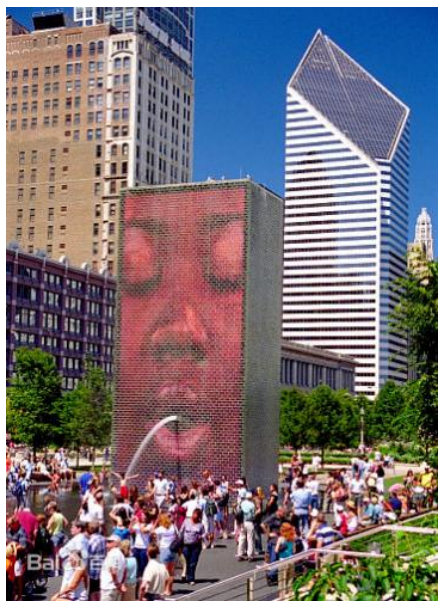

Fig. 3. Crown Fountain. 


\section{B. Interaction between Public Art and Public Space}

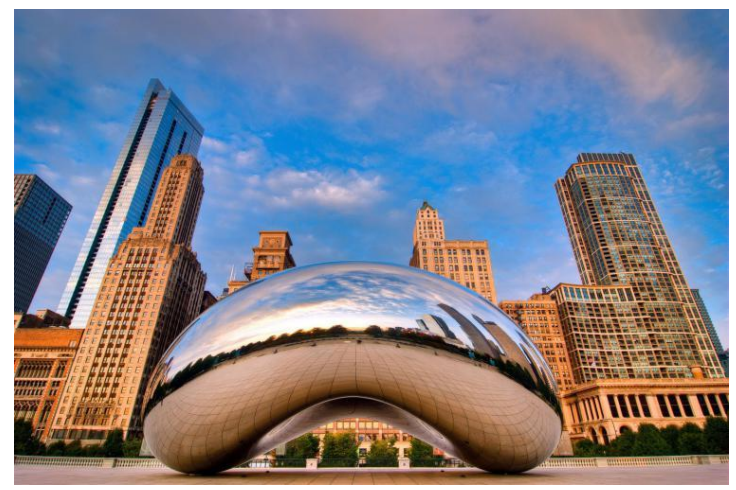

Fig. 4. Cloud Gate.

The interaction between good public art and public space makes public space have special space atmosphere, the atmosphere has gained public recognition, and this sense of identity slowly becomes a sense of belonging to the public spirit in the long accumulation. What is more, this public space has been given permanent charm because of this spiritual sense of belonging and the essence of public space has been enhanced. No matter what is the form of the public space art in public space, a simple painting, an abstract sculpture or an inconspicuous public facility, this public space can interact with space and the public again. Designed by Indian artist Anish Kapoor's cloud gate in "Fig. 4", it is located in millennium plaza, Chicago, USA. The work has a distinctive pattern of arc features, like floating clouds that are impressive. The idiosyncratic form makes the image of the tourist reflect on its image in different ways, which produces a high degree of interaction with the surrounding environment.

\section{INFLUENCE FACTORS OF CAMPUS PUBLIC ART INTERACTIVE DESIGN}

\section{A. People-oriented Design Concept}

The public art construction of the school should take the teachers and students as the main service object and create a good public space for the teachers and students. The expression form, shape, scale, color, material and technique of public space art should all follow the idea of human centered design. Some schools have a metal seat. Under the summer sun, the high temperature makes it impossible for the seat to be used. We should take into account the problems that people will use and make corresponding adjustments when designing. If the design violates the principle of human nature and makes the user reluctant to obey the design, the design will lose its meaning. It has no practical effect. In contrast, it will waste resources and occupies space.

\section{B. The Cultural Heritage of Interactive Public Art on Campus}

The history, culture and style of a place are recorded in the historical context and the school is the same. Through the window of historical context, we can see the course of the school. So how does the historical context of the campus show themselves to the teachers and students on campus? Public art is one of the best ways to present it. Public art shows the tangible historical context through its various forms to make the campus space full of cultural charm and let the teachers and students feel the different campus atmosphere in silence. The history of the campus has been advancing, and the historical context is the characteristic of the campus. The history and culture of the campus are also continued in the interaction between teachers and students. On the basis of this development, the campus will continue to grow and develop.

\section{The Carrier of the Interactive Public Art on Campus}

The campus public space is the carrier of the public art of the campus and the lack of campus public space is the most common problem in the construction and development of many schools. The functions of different public spaces are different and we should grasp the principle of adapting to local conditions in the process of design. If you can set up some decorative frescoes on the walls on both sides of the school's teaching building corridor, it not only beautifies the corridor space, but also shows a concentrated expression of the campus culture. The construction of a reasonable campus should have public space for public space art. The introduction of public art can make public space more accessible and further build a pleasant public space on campus.

\section{The Suggestion On THE INTERACtive Design OF THE CAMPUS PuBLIC ART}

The design of campus public space art is to make the campus better, enrich the campus culture and create a more humanized public space for teachers and students. In order to promote the realization of the interaction of public art, I put forward some suggestions:

\section{A. To Provide Construction System Guarantee for Campus Public Art}

In the 1950s, New York, Philadelphia and other cities in the United States promulgated the "Art percentage act" in order to regulate the development of public art. The implementation of this law provides important institutional guarantee for the application of public art to campus construction. The construction of campus public art in China can also draw lessons from the American art "percentage act", establish the system of the construction of the campus public art according to the actual conditions to ensure the normal and orderly development of the campus public art.

\section{B. To Improve the Public Participation}

In order to enable public art to better interact and communicate with teachers and students, the basic measures that can be taken are: name the public art, set up the propaganda column to explain the idea, set up a regular maintenance program, and provide more temporary public art activities, etc. Encourage school members to participate in the design process and the features of the school and the desired school style should be discussed on the basis of the 
uniqueness of the school environment. In the course of the design of the campus public art in the future, more suggestions should be adopted by the teachers and students. Understand the imagination and expected effect of teachers and students on the public art of campus through the questionnaire or the form of the symposium. Let students really be involved in it. Improve the participatory and interaction of teachers and students from fundamental measures and increase the lively atmosphere of Campus.

\section{To Create the Interactive Conditions between the Teachers and Students and the Public Art of the Campus}

Let the teachers and students participate in the discussion of the final style desired by the school and enhance the students' interest in artistic creation and the sense of identity of campus environment when the school is built and planning to set up the campus public art. Because of the display of the works, the campus is full of beauty. At the same time, it also provided a good model for the later teachers and students. The design instructions are attached after the completion of the work to allow students to copy or sketch, to participate in the evaluation, or to discuss and appreciate the course. Let campus public art works really enter the life of teachers and students. At the same time, put the campus public works of art on the campus web site or the school Brochure. Explain the source, process, and the significance of the works to improve the communication and approval of the society and the parents.

\section{CONCLUSION}

Public art started late in China, the public space of the campus has not completely become a place for the communication of the main body, and the construction of public art does not fully meet the needs of the main body. The formalization and similarity of the art of the campus public space should be improved. This is the reason why this article emphasizes the interactive nature of the campus public art. The interactive nature of public space art doomed the public space of the campus to be the public space of the main body and the subject can participate in the construction of public space. In the participation, the subject will pass on the history and culture of the campus. This transmission not only includes the transmission of the public space constructed by the subject, but also the inheritance of the inner environment of the main body to the campus history and culture, making public art could better integrate into campus construction and campus culture.

\section{REFERENCES}

[1] [Germany] Hegel. Translated by Zhu Guangqian. Aesthetic [M]. Beijing, The Commercial Press, 1979

[2] Zhou Yihu, Song Fangze. Architecture of Higher Education·Planning and Environmental Design [M]. Beijing, China Construction Industry Press, 1994

[3] Shenzhen Sculpture Institute. One Day of the People of Shenzhen[M] Changsha, Hunan Art Publishing House, 2001

[4] Shi Hui. A public art report from the campus [M]. Hangzhou, The China Academy of Art press, 2007.
[5] Gao Ya. Research on campus advertising art construction based on campus culture[D]. Master's Degree Thesis of HeFei University of Technology,2001

[6] Ma Jun, Jiang Ying. Short term public artistic creation under the context of comprehensive university campus culture-Take Zhejiang University of Technology as an example[J]. Decorate, 2004. 